\title{
PENGEMBANGAN TES PENGETAHUAN GAMBAR TEKNIK BERBASIS WEBSITE
}

${ }^{1}$ Sella Kurniawati, ${ }^{2}$ Soeprijanto, ${ }^{3}$ Faried Wadjdi

${ }^{1,2,3}$ Pendidikan Teknik ElektroTeknik Elektro, Universitas Negeri Jakarta

\begin{abstract}
This Research and development determines the effectiveness of media usage test based on website when compared with conventional test, for the final exam related to basic knowledge of engineering drawings on electrical engineering major of a vocational school called Teknik Instalasi Pemanfaatan Tenaga Listrik (TIPTL).

The research was conducted at SMKN, a public vocational high school, from August 2016 until December 2016. The method used in this research is Research and Development while the ADDIE model (Analysis, Design, Development, Implentation, and Evaluation). The data was collected by using a questionnaire for measuring the feasibility of the media and the effectiveness formula is used to determine the effectiveness of aformentioned media.

Based on research that has been conducted, the test of testing by subject matter experts indicate that the product got $92 \%$, the results of testing by media experts got $89 \%$, and the results of testing by students $88 \%$. Then, the development of knowledge technical drawing test based on website can be expressed very worthy to be used. The results of the comparing the efficacy score between web-based test with conventional test shows, the effectiveness score of conventional test $\left(E_{T K}\right)$ is 0.015 , and the effectiveness score of web-based test $\left(E_{T B W}\right)$ is 0.12. Based on that comparison $E_{T K}<E_{T B W}$, because the effectiveness score of conventional test is lesser then effectiveness score of web-based test $\left(E_{T B W}\right)$ it can be said that web-based test of basic konwledge of engineering drawing is effective enough to be used for final exam at TIPTL major of SMKN 26.
\end{abstract}

Keywords: Basic Knowledge of Engineering Drawings, Development, Effetiveness Score, Electrical Engineering, Test

\begin{abstract}
Abstrak
Penelitian dan pengembangan ini bertujuan untuk mengetahui kelayakan dan nilai keefektifan penggunaan media tes berbasis website apabila dibandingkan dengan tes konvensional untuk pelaksanaan Ujian Akhir Semester (UAS) terkait materi pengetahuan dasar gambar teknik yang terdapat pada program studi Teknik Instalasi Pemanfaatan Tenaga Listrik (TIPTL).

Penelitian dilakukan di Sekolah Menengah Kejuruan Negeri (SMKN) 26 Jakarta dari bulan Agustus 2016 sampai Desember 2016. Metode penelitian yang digunakan adalah metode penelitian dan pengembangan (Research \& Development) sedangkan model pengembangan produk yang digunakan adalah model ADDIE (Analysis, Design, Development, Implentation, dan Evaluation). Proses pengumpulan data melalui kuesioner penilaian untuk mengukur kelayakan media dan digunakan rumus efektivitas untuk mengetahui nilai keefektifan tes berbasis website ini.

Berdasarkan hasil penilaian kelayakan, hasil penilaian oleh ahli materi memperoleh presentase $92 \%$, hasil penilaian oleh ahli mediasebesar $89 \%$, dan hasil penilaian oleh siswa sebesar $88 \%$. Maka media tes pengetahuan gambar teknik berbasis website dinyatakan sangat layak untuk digunakan. Berdasarkan hasil perbandingan nilai keefektifan antara tes berbasis website dengan tes konvensional, diperoleh nilai keefektifan Tes Konvensional ( $\left.\mathrm{E}_{\mathrm{TK}}\right)$ sebesar 0,015 dan nilai Efektivitas Tes Berbasis Website ( $\left.\mathrm{E}_{\mathrm{TBW}}\right)$ sebesar 0,12. Berdasarkan nilai keefektifan tersebut dinyatakan bahwa perbandingan $E_{T K}<E_{T B W}$, karena nilai keefektifan tes konvensional lebih kecil daripada nilai keefektifan tes berbasis website maka dapat dikatakan pengembangan tes pengetahuan gambar teknik dalam bentuk website ini efektif dijadikan media pendukung dalam melaksanakan Ujian Akhir Semester (UAS) di Sekolah Menengah Kejuruan (SMK) pada Program Studi Teknik Instalasi Pemanfaatan Tenaga Listrik (TIPTL).
\end{abstract}

Kata kunci: Pengetahuan Gambar Teknik, Pengembangan, Nilai Keefektifan, Teknik Elektro, Tes

\section{PENDAHULUAN}

Kegiatan penelitian ini berawal dari Sistem Tes yang selama ini bersifat (konvensional) yaitu tes dilakukan dengan menggunakan kertas dan pensil, diistilahkan dengan Paper-Based Test (PBT). PBT yang dilakukan saat ini masih terdapat beberapa masalah/kendala, diantaranya: rawan kebocoran soal dalam mempersiapkan bahan tes, penggandaan dan distribusi naskah soal karena banyaknya pihak yang terlibat, kecurangan peserta didik selama pelaksanaan tes, diperlukannya langkah scanning dan scoring LJK,semua itu membutuhkan biaya, tenaga, waktu dan SDM yang tidak sedikit. Sehingga PBT dianggap kurang efektif dan efisien.

Sehubungan dengan diadakannya Ujian Nasional Berbasis Komputer (UNBK), disebut 
juga dengan Computer Based Test (CBT) yang merupakan suatu sistem pelaksanaan tes nasional dengan menggunakan komputer sebagai media tesnya. Berdasarkan data yang didapat dari website uncbt.com pertama kali dilaksanakannya Ujian Nasional Berbasis Komputer (UNBK) di Sekolah Menengah Kejuruan (SMK) berlangsung pada bulan April 2016.

Terkait dengan UNBK (Ujian Nasional Berbasis Komputer) setiap peserta didik diberikan username (nama pengguna) dan password (kata sandi) yang akan digunakan pada media tes berbasis website ini. Username disesuaikan dengan nama lengkap masingmasing siswa, sedangkan password diambil dari kode sekolah-kelas-3 digit akhir nomer induk siswa (NIS). Biodata yang perlu diisi dari masing-masing siswa akan muncul setelah username dan password yang dimasukkan benar. Setelah itu, siswa baru dapat mulai mengerjakan soal tes. Rumitnya melaksanakan serangkaian proses tersebut pada kali pertama, dikhawatirkan dapat menghambat dan menjadikan UNBK (Ujian Nasional Berbasis Komputer) tidak kondusif, sehingga diperlukan pembiasaan atau latihan agar kekhawatiran tidak terjadi.

Adanya media tes online ini kegiatan evaluasi pembelajaran pun dapat berjalan lebih efektif karena siswa tidak mempunyai banyak kesempatan untuk mencontek dengan siswa lainnya. Hal itu dikarenakan, sistem tes berbasis website ini akan mengacak urutan soal-soal yang muncul dan mengacak urutan pilihan jawabannya juga. Melalui media tes berbasis website ini diharapkan siswa dapat membiasakan diri dalam mengikuti ujian berbasis komputer yang bersifat onlilne. Karena tidak sedikit diantara peserta didik yang belum terbiasa mengerjakan soal-soal tes berbasis website. Media tes ini ini akan diuji cobakan disalah satu Sekolah Menengah Kejuruan (SMK) di Jakarta yang memiliki Kompetensi Keahlian Teknik Instalasi Pemanfaatan Tenaga Listrik (TIPTL).

Salah satu mata pelajaran yang harus dipelajari oleh siswa kelas $\mathrm{X}$ Kompetensi Keahlian Teknik Instalasi Pemanfaatan Tenaga Listrik (TIPTL) adalah mata pelajaran Gambar
Teknik, mata pelajaran produktif yang terdiri dari pengetahuan dan keterampilan, akan tetapi yang diujikan dalam tes yang akan dibuat hanya dalam ranah pengetahuannya saja. Rendahnya penguasaan terhadap pengetahuan Gambar Teknik akan sangat mempengaruhi proses belajar mengajar selanjutnya, karena Gambar Teknik mempelajari dasar-dasar pengetahuan menggambar yang baik dan benar.

Dari latar belakang di atas, penulis berniat untuk mengembangkan tes yang selama ini bersifat konvensional menjadi tes berbasis komputer yang bersifat online. Dengan adanya "Pengembangan Tes Pengetahuan Gambar Teknik Berbasis Website" diharapkan dapat menjadi media tes yang dapat mendukung pelaksanaan Ujian Akhir Semester (UAS) di Sekolah Menengah Kejuruan (SMK). Selain itu adanya sistem penilaian otomatis yang bersifat online ini dapat membantu para guru dalam melihat hasil belajar siswanya.

\section{METODE}

Metode pengembangan dalam penelitian yang akan dilaksanakan adalah metode penelitian dan pengembangan (Research and Development). Salah satu model atau pendekatan desain sistem pembelajaran yang dapat diimplementasikan untuk mendesain dan mengembangkan program pelatihan yang efektif dan efisien adalah model ADDIE. Model desain sistem pembelajaran ADDIE bersifat sederhana dan dapat dilakukan secara bertahap. Tahaptahap kegiatan yang terdapat dalam model ADDIE terdiri sebagai berikut (Pribadi, 2014:23) :

1. Langkah 1. Analisis (Analysis) merupakan tahap pertama dalam menerapkan model ADDIE untuk mendesain dan mengembangkan sebuah program. Pada tahap ini peniliti perlu melakukan proses analisis kebutuhan awal. Dalam melakukan proses analisis kebutuhan, peneliti harus mengumpulkan data dan informasi terkait dengan identifikasi masalah penelitian pada bab 1.

2. Langkah 2. Desain (Design dilakukan dengan membuat rancangan desain yang menggambarkan rencana tampilan tes. Dalam tahap desain juga ditetapkan rencana 
penggunaan penggunaan strategi pembelajaran dan instrumen sebagai evaluasi yang digunakan untuk menilai hasil belajar yang dicapai oleh peserta didik.

3. Langkah 3. Pengembangan (Development). Merupakan proses mewujudkan desain menjadi kenyataan. Artinya pada tahap ini segala sesuatu yang dibutuhkan atau yang akan mendukung proses pembelajaran semuanya harus disiapkan.

4. Langkah 4. Implementasi (Implementation). Merupakan langkah nyata untuk menerapkan sistem tes yang sedang dibuat. Artinya, pada tahap ini semua yang telah dikembangkan diinstal atau diset sedemikian rupa sesuai dengan peran atau fungsinya agar bisa diimplementasikan. Satu langkah penting dalam tahap pengembangan ini adalah uji coba sistem sebelum diiplementasikan, yang kemudian dievaluasi dan direvisi.

5. Langkah 5. Evaluasi (Evaluation) adalah proses untuk melihat apakah sistem pembelajaran yang sedang dibangun berhasil, sesuai dengan harapan awal atau tidak. Tahap evaluasi bisa dilakukan pada setiap empat tahap diatas yang disebut evaluasi formatif, karena tujuannya untuk kebutuhan revisi.

\section{HASIL DAN PEMBAHASAN}

Berdasarkan hasil angket analisis kebutuhan awal yang telah disebarkan maka data yang peroleh sebagai berikut:

Tabel 1. Hasil Analisis Kebutuhan Awal

\begin{tabular}{llcc}
\hline \multirow{2}{*}{ No } & \multicolumn{1}{c}{ Pertanyaan } & Ya & Tidak \\
\hline 1 & Apakah kamu mengetahui & 19 & $\mathbf{1 1}$ \\
& tentang UNBK (Ujian Nasional & siswa & siswa \\
& Berbasis Komputer)? & $(37 \%)$ & $(\mathbf{6 3 \%})$ \\
2 & Apakah dalam keseharian kamu & $\mathbf{2 0}$ & 10 \\
& sering menggunakan komputer? & siswa & siswa \\
& & $(\mathbf{6 7 \%})$ & $(33 \%)$ \\
3 & Apakah kamu pernah & 10 & $\mathbf{2 0}$ \\
& mengerjakan tes di website & siswa & siswa \\
& secara online? & $(33 \%)$ & $(\mathbf{6 7 \%})$ \\
& Apakah kamu setuju jika tes & $\mathbf{2 2}$ & 8 \\
& dilaksanakan secara online? & siswa & siswa \\
& & $(\mathbf{7 3 \% )}$ & $(27 \%)$ \\
5 & Apakah kamu pernah & 8 & $\mathbf{2 2}$ \\
& mengerjakan tes tentang & siswa & siswa \\
& pengetahuan dasar pada & $(27 \%)$ & $\mathbf{( 7 3 \% )}$ \\
& pelajaran Gambar Teknik? & & \\
Apakah kamu pernah & 5 & $\mathbf{2 5}$ \\
& mendengar website yang berisi & siswa & siswa \\
& & $(17 \%)$ & $\mathbf{( 8 3 \% )}$ \\
\hline
\end{tabular}

\begin{tabular}{|c|c|c|c|}
\hline & $\begin{array}{l}\text { tes/soal dengan mata pelajaran } \\
\text { Gambar Teknik? }\end{array}$ & & \\
\hline 7 & $\begin{array}{l}\text { Apakah kamu pernah } \\
\text { menggunakan website yang } \\
\text { berisi tes/soal dengan mata } \\
\text { pelajaran Gambar Teknik? }\end{array}$ & $\begin{array}{c}4 \\
\text { siswa } \\
(13 \%)\end{array}$ & $\begin{array}{c}26 \\
\text { siswa } \\
(87 \%)\end{array}$ \\
\hline 8 & $\begin{array}{l}\text { Apakah guru kamu pernah } \\
\text { menggunakan website yang } \\
\text { berisi tes/soal dengan mata } \\
\text { pelajaran Gambar Teknik } \\
\text { sebagai media tes/ujian secara } \\
\text { online? }\end{array}$ & $\begin{array}{c}5 \\
\text { siswa } \\
(17 \%)\end{array}$ & $\begin{array}{c}25 \\
\text { siswa } \\
(\mathbf{8 3 \%})\end{array}$ \\
\hline 9 & $\begin{array}{l}\text { Apakah kamu mendukung } \\
\text { rencana pengembangan tes } \\
\text { pengetahuan gambar teknik } \\
\text { untuk menunjang kegiatan } \\
\text { UAS (Ujian Akhir Semester) di } \\
\text { sekolah? }\end{array}$ & $\begin{array}{c}27 \\
\text { siswa } \\
(90 \%)\end{array}$ & $\begin{array}{c}3 \\
\text { siswa } \\
(10 \%)\end{array}$ \\
\hline 10 & $\begin{array}{l}\text { Apakah kamu setuju jika } \\
\text { website digunakan sebagai } \\
\text { sarana tes berbasis website } \\
\text { pada mata pelajaran Gambar } \\
\text { Teknik? }\end{array}$ & $\begin{array}{c}25 \\
\text { siswa } \\
(83 \%)\end{array}$ & $\begin{array}{c}5 \\
\text { siswa } \\
(17 \%)\end{array}$ \\
\hline
\end{tabular}

Dikarenakan belum adanya sarana tes berbasis website untuk siswa SMK (Sekolah Menengah Kejuruan) terutama terkait materi pengetahuan dasar gambar teknik, hampir seluruh siswa mendukung rencana pengembangan tes pengetahuan gambar teknik yang akan diterapkan saat

Ujian Akhir Semester (UAS) yaitu 83\% siswa. Berdasarkan data tersebut peneliti menganggap perlu adanya pengembangan tes berbasis website pada mata pelajaran Gambar Teknik untuk siswa kelas X TIPTL sehingga dapat membiasakan siswa mengerjakan tes secara online sejak awal semester.

\section{Rancangan Desain Tampilan Tes Berbasis Website}

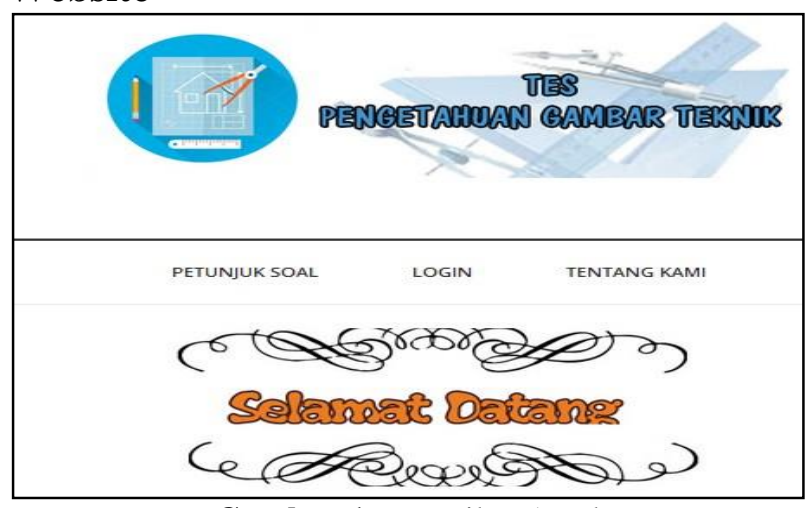

Gambar 1. Tampilan Awal 


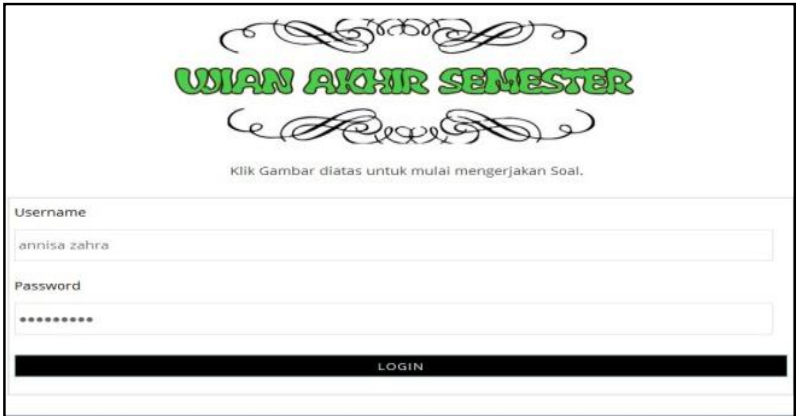

Gambar 2. Login

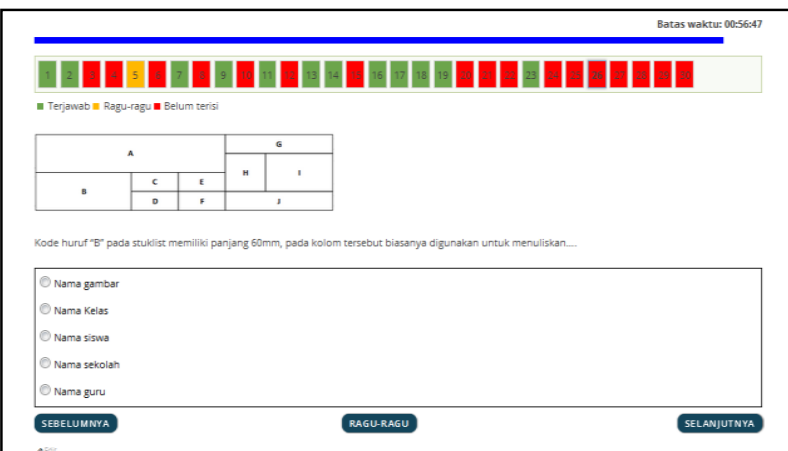

Gambar 3. Tampilan saat Mengerjakan Soal

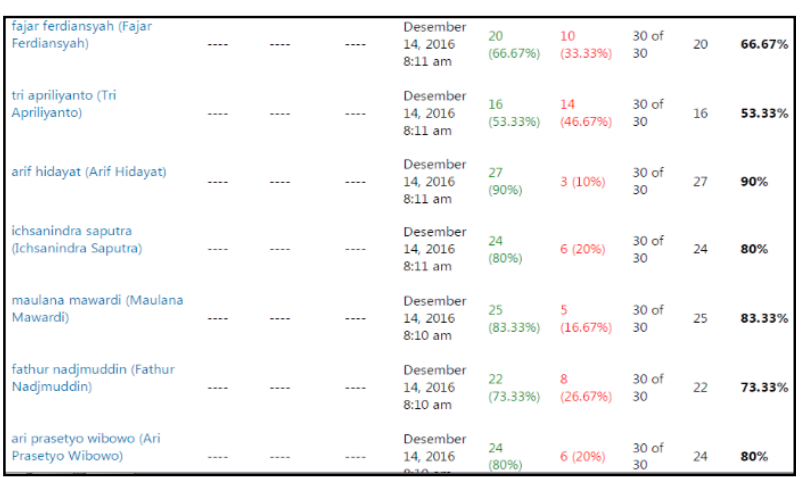

Gambar 4. Rekapan Nilai Ujian Siswa

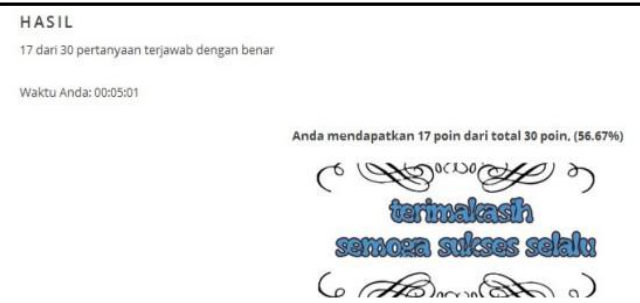

Gambar 5. Tampilan Setelah Selesai Mengerjakan Ujian

\section{Penilaian oleh Para Ahli}

Media tes berbasis website yang sudah dibuat selanjutnya akan divalidasi terlebih dahulu oleh 2 orang ahli materi. Berikut ini diagram batang hasil kuesioner dan histogram uji kelayakan oleh ahli materi

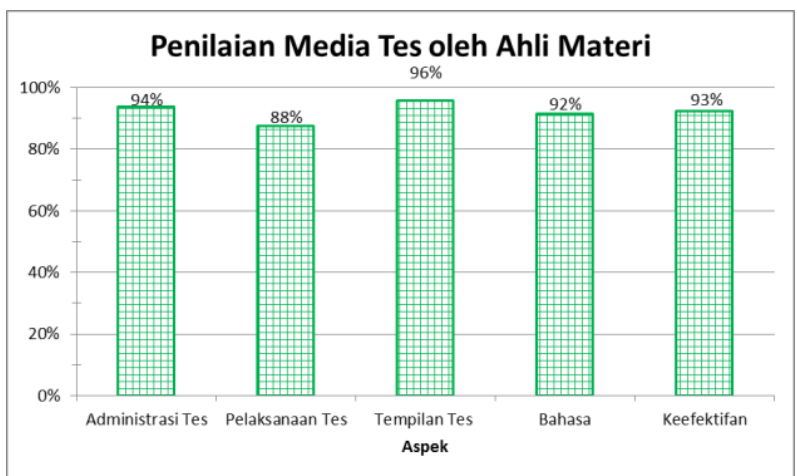

Gambar 6. Diagram Batang Penilaian Ahli Materi

Berikut ini diagram batang hasil kuesioner dan histogram uji kelayakan oleh ahli media:

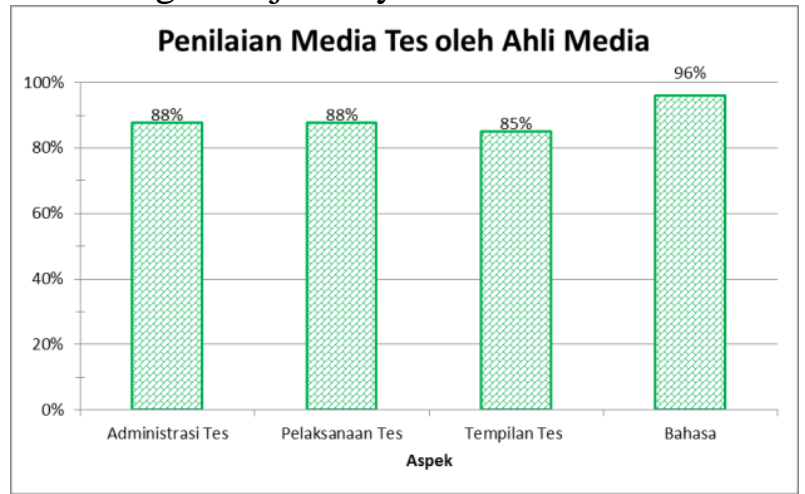

Gambar 7. Diagram Batang Penilaian Ahli Media

Berdasarkan hasil penilaian diatas, diperoleh nilai rata-rata oleh ahli materi sebesar $92 \%$, nilai rata-rata oleh ahli media sebesar $89 \%$, Setelah dinyakatakan layak dari para ahli, media tes diujicobakan kepada siswa, berikut diagram batang hasil penilaian oleh siswa.

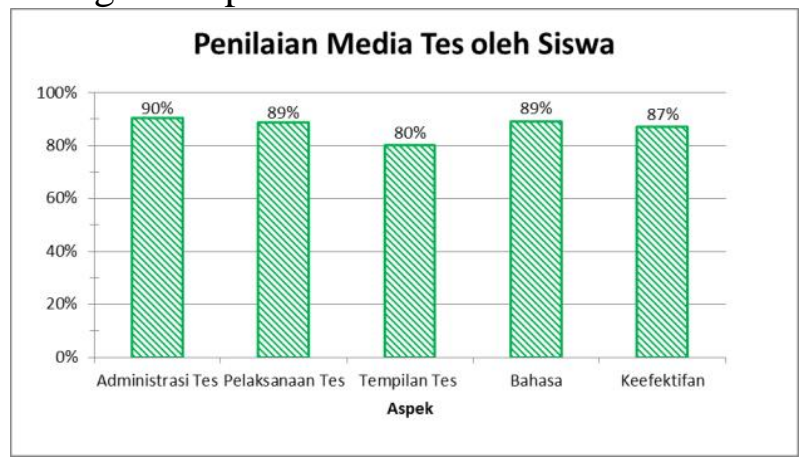

Gambar 8. Diagram Batang Penilaian Siswa

Agar terlihat perbedaan keefektifan masingmasing tes maka penilaian terfokus pada perbedaannya, kejadian yang sama pada kedua tes akan diabaikan. Dikarenakan tujuan yang ingin dicapai (outcome) dari tes berbasis website dan tes konvensional adalah sama-sama untuk mendapatkan hasil evaluasi belajar, maka 
outcome dari tes berbasis website dan tes konvensional adalah sama, jadi diambillah angka 1 (satu). Sehingga untuk melihat keefektifannya dilihat dari nilai output yang dipergunakan dari masing-masing tes.

Tabel 2. Perbandingan Nilai Output Tes

Konvensional dan Tes Berbasis Website

\begin{tabular}{|c|c|c|c|c|}
\hline $\begin{array}{l}\text { Urutan } \\
\text { Proses }\end{array}$ & $\begin{array}{c}\text { Tes } \\
\text { Konven- } \\
\text { sional }\end{array}$ & $\begin{array}{l}\text { Out- } \\
\text { put }\end{array}$ & \begin{tabular}{l}
\multicolumn{1}{c}{ Tes } \\
Berbasis \\
Website
\end{tabular} & $\begin{array}{l}\text { Out } \\
-p u t\end{array}$ \\
\hline $\begin{array}{l}\text { 1.Pem- } \\
\text { buatan } \\
\text { Variasi } \\
\text { Soal }\end{array}$ & $\begin{array}{l}\text { Sekitar } 15 \\
\text { menit }\end{array}$ & 1,5 & $\begin{array}{l}\text { Soal dapat } \\
\text { teracak }\end{array}$ & 0 \\
\hline \multirow{2}{*}{$\begin{array}{l}\text { 2.Distri- } \\
\text { busi Soal }\end{array}$} & $\begin{array}{l}\text { a.Distribusi } \\
\text { awal }\end{array}$ & 2 & $\begin{array}{l}\text { Soal ujian } \\
\text { sudah } \\
\text { terdapat }\end{array}$ & $\begin{array}{c}0,00 \\
8\end{array}$ \\
\hline & $\begin{array}{l}\text { b.Distribusi } \\
\text { akhir }\end{array}$ & 2 & $\begin{array}{l}\text { dalam } \\
\text { sistem }\end{array}$ & $\begin{array}{c}0,00 \\
8\end{array}$ \\
\hline \multirow[b]{2}{*}{$\begin{array}{l}\text { 3.Pelaksa- } \\
\text { naan Tes }\end{array}$} & $\begin{array}{l}\text { Waktu } \\
\text { mengerjakan } \\
\text { selama } 2 \\
\text { jam }\end{array}$ & 12 & $\begin{array}{l}\text { a. Waktu } \\
\text { mengerjak } \\
\text { an selama } \\
1 \text { jam }\end{array}$ & 6 \\
\hline & $\begin{array}{l}\text { Jumlah } \\
\text { orang yang } \\
\text { terlibat } 3 \\
\text { pihak }\end{array}$ & 3 & $\begin{array}{l}\text { b. Jumlah } \\
\text { orang } \\
\text { yang } \\
\text { terlibat } 2 \\
\text { pihak }\end{array}$ & 2 \\
\hline $\begin{array}{l}\text { 4.Koreksi } \\
\text { Jawaban }\end{array}$ & $\begin{array}{l}\text { Waktu } \\
\text { koreksi }\end{array}$ & 45 & $\begin{array}{l}\text { penilaian } \\
\text { otomatis }\end{array}$ & $\begin{array}{c}0,00 \\
8\end{array}$ \\
\hline & Output $_{T K}$ & \multicolumn{3}{|c|}{ Output ${ }_{T B W}$} \\
\hline Nilai & $=65,5$ & \multicolumn{2}{|c|}{$=8,024$} & \\
\hline
\end{tabular}

Nilai efektivitas akan didapat dari perbandingan nilai ujian siswa (outcome) dibagi dengan nilai output akhir.

Tabel 3. Perhitungan Nilai Keefektifan

\begin{tabular}{ccl}
\hline Rumus & $\begin{array}{c}\text { Tes } \\
\text { Konvensional }\end{array}$ & \multicolumn{1}{c}{$\begin{array}{c}\text { Tes Berbasis } \\
\text { Website }\end{array}$} \\
\hline Efektivitas* & $\begin{array}{c}\text { Efektivitas }= \\
\text { nilai ujian siswa }\end{array}$ & $\begin{array}{l}\text { Efektivitas }= \\
\text { nilai ujian siswa }\end{array}$ \\
\cline { 2 - 3 } oUTCOME & nilai output akhir & nilai output akhir \\
& $=\frac{1}{65,5}$ & $=\frac{1}{8,024}$ \\
& $E_{T K}=0,015$ & $E_{T B W}=0,12$ \\
\hline$E_{T K}<E_{T B W}$ \\
$0,015<0,12$ \\
EFEKTIF \\
kearena nilai keefektifan tes konvensional < nilai \\
keefektifan tes berbasis website maka dapat dikatakan \\
tes berbasis website lebih efektif \\
\hline
\end{tabular}

\section{KESIMPULAN DAN SARAN}

\section{Kesimpulan}

Berdasarkan hasil penilaian dan uji kelayakan yang dilakukan oleh para ahli materi, ahli media, yang masing-masing memberikan saran yang kemudian dijadikan evaluasi untuk memperbaiki media tes. Hasil penilaian berupa presentase nilai sebesar $92 \%$ yang diberikan oleh ahli materi, yang menunjukkan bahwa media tes sangat layak. Presentase nilai sebesar $89 \%$ diberikan oleh ahli media yang menunjukkan bahwa media tes sangat layak. Pada uji coba lapangan dengan melibatkan 30 siswa sebagai peserta ujian tes berbasis website, memperoleh presentase nilai sebesar $88 \%$ yang menunjukkan bahwa media tes sangat layak.

Pada uji keefektifan antara tes konvensional dan tes berbasis website diperoleh nilai keefektifan tes konvensional sebesar 0,015 dan nilai keefektifan tes berbasis website sebesar 0,12 . Nilai keefektifan tes konvensional yang lebih kecil daripada nilai keefektifan tes berbasis website. Menunjukkan bahwa tes berbasis website lebih efektif dijadikan media tes pengetahuan teknik dalam melaksanakan Ujian Akhir Semester (UAS) di Sekolah Menengah Kejuruan (SMK).

Dengan melakukan ujian secara online siswa mengerjakan tes yang berbeda karena soal dan urutan pilihan jawaban sudah diacak oleh sistem yang ada pada wp-pro-quiz, sehingga dapat meminimalisir kecurangan siswa. Dengan adanya media tes berbasis website ini, data siswa beserta nilai yang sudah diperolehnya dapat dilihat langsung dan akan tersimpan dalam akun guru untuk kemudian bisa dilihat kapan dan dimana saja oleh guru.

\section{Saran}

1. Dari segi media, media tes berbasis webiste ini dapat dimanfaatkan agar bisa digunakan untuk ujian mata pelajaran lain.

2. Disarankan kepada peneliti lain untuk mengadakan penelitian dan pengembangan lebih lanjut mengenai tes berbasis website menggunakan aplikasi lain yang lebih mendukung dan lebih lengkap. Sehingga dapat membuat tes berbasis website yang di dalamnya juga bisa melakukan analisis butir soal. 
3. Untuk para pakar wordpress, agar dapat melakukan inovasi baru, dengan menambahkan Plugin baru pada wordpress yang dapat mendukung agar dapat dilengkapi dengan program tes yang memungkinkan untuk melakukan analisis butir soal.

\section{DAFTAR PUSTAKA}

A. V. Kelly. (2006). The Curriculum Theory and Prantice. London:Sage Production.

Arikunto, Suharsimi. (2002). Dasar-dasar Evaluasi Pendidikan. Jakarta: PT.Bumi Aksara.

Daryanto. (2011). Media Pembelajaran. Bandung: PT. Sarana Tutorial Sejahtera.

Effendy, Onong Uchjana. (1989). Kamus Komunikasi. Bandung : PT.Mandar Maju

Hariyanto, M.S. (2014). Asesmen Pembelajaran. Bandung: PT. Remaja Rosdakarya.

Hanson, Ward. (2000). Pemasaran Internet. Jakarta: Salemba Empat

Hardjono, Dhewiberta. (2006). Seri Panduan Lengkap Menguasai Pemrograman Web dengan PHP 5. Yogyakarta: C.V Andi Offset.

[FT] Fakultas Teknik. 2015. Buku Panduan Penyusunan Skripsi dan Non Skripsi. Jakarta: Fakultas Teknik, Universitas Negeri Jakarta.

Janner, Simarmata. (2006). Pengenalan Teknologi Komputer dan Informasi. Yogyakarta :Andi.

John, Schemerhon. (1986). Management for Productivity. Australia: The University of Michigan.

Komariah, Aan. (2006). Visionary Leadership. Jakarta: Bumi Aksara.

Mahmudi. (2005). Manajemen Kinerja Sektor Publik. Yogyakarta: UPP AMP YKPN.

Mahmudi. (2015). Manajemen Kinerja Sektor Publik. Yogyakarta: Sekolah Tinggi Ilmu Manajemen YKPN.

Mardapi, Djemari. (2012). Pengukuran, Penilaian, dan Evaluasi Pendidikan. Yogyakarta : Nuha Medika.

Miskiyah, Evi. 2013. Pengembangan Instrumen Asesmen dengan Teknik Simulasi sebagai Asesmen Alternatif dalam Pembelajaran Fisika [skripsi]. Yogyakarta: Fakultas Sains dan Teknologi, Universitas Sunan Kalijaga.
Purwanto. (2011). Evaluasi Hasil Belajar. Yogyakarta: Pustaka Pelajar.

Putra, Sitiatava Rizema. (2013). Desain Evaluasi Belajar Berbasis Kinerja. Bandung : PT. Remaja Rosdakarya.

Prasetya, Arya Bima. 2015. Pengembangan Latihan Soal Ujian Nasional Matematika Tingkat SMA Online Berbasis Web Menggunakan CMS Drupal: studi kasus di SMKN 1 Purwoharjo [skripsi]. Banyuwangi: Fakultas Keguruan dan Ilmu Pendidikan, Universitas Negeri Jember.

M. Sukardi, (2009). Evaluasi Pendidikan. Jakarta: PT. Bumi Aksara.

Ratnawulan, Elis \& Rusdiana A. (2014). Evaluasi Pembelajaran. Jawa Barat: CV Pustaka Setia.

Rusman. K \& Deni. R, Cepi. (2010). Media Pendidikan: pengertian, pengembangan dan pemanfaatannya. Jakarta: Rajawali.

Setiaji, Dhani Harda. 2016. Pengembangan Media Computer Assisted Instruction (CAI) untuk Perhitungan Volume Pekerjaan dan Analisis Biaya Bahan: studi kasus di SMKN 4 Rorotan [tesis]. Jakarta: Program Pascasarjana

Sudjana, Nana. (2008). Penilaian Hasil Proses Belajar Mengajar. Bandung : PT. Remaja Rosdakarya.

Sudjiono, Anas. (1996). Pengantar Evaluasi Pendidikan. Jakarta: PT.Grafindo Persada.

Sudijono,Anas. (2010). Pengantar Statistik Pendidikan, Jakarta: Rajawali Pers.

Sugiyono. (2011). Metode Penelitian Pendidikan. Bandung: Alfabeta

Supriono, Agus. (2013). Cooperative Learning Teori dan Aplikasi PAIKEM. Yogyakarta: Pustaka Pelajar.

Susanto, Astrid S. (1975). Efektifitas. Bandung: Bina Cipta

Suyanto. (2003). E-commerce Perusahaan Top Dunia. Yogyakarta: Andi. 